\title{
Short communication: Opposing effects of lactoferrin on the proliferation of fibroblasts and epithelial cells from bovine mammary gland
}

\author{
K. Nakajima, ${ }^{* 1}$ F. Itoh, ${ }^{*}$ M. Nakamura, ${ }^{*}$ A. Kawamura, ${ }^{*}$ T. Yamazaki, ${ }^{*}$ T. Kozakai, ${ }^{*}$ N. Takusari, ${ }^{*}$ and A. Ishisaki† \\ *NARO Hokkaido Agricultural Research Center, Hitsujigaoka 1, Toyohira, Sapporo 062-8555, Japan \\ †Department of Biochemistry, Iwate Medical University School of Dentistry, Nishitokuta, Yahaba-cho, Iwate 028-3694, Japan
}

\section{ABSTRACT}

Lactoferrin is present in several physiologic fluids, including milk and colostrum. Recently, evidence has accumulated that lactoferrin acts as a regulator of cell proliferation. Lactoferrin mRNA and protein levels in bovine mammary glands are known to markedly increase after cessation of milking. To clarify the role of bovine lactoferrin (bLF) in mammary involution and remodeling during dry periods, we investigated whether bLF affects the proliferation of cultured cells derived from bovine mammary gland and examined the mechanism underlying the proliferative response to bLF. Addition of bLF to the culture medium increased the proliferation of bovine mammary stromal fibroblasts (bMSF), but decreased that of bovine mammary epithelial cells (bMEC). Proliferation was significantly increased in the bMSF treated with bLF $(100 \mu \mathrm{g} / \mathrm{mL}$ or greater $)$ as compared with unstimulated cells. The maximal proliferative effect of bLF on bMSF occurred at 1,000 $\mu \mathrm{g} / \mathrm{mL}$, such that the proliferation of the bLF-stimulated bMSF was approximately 2.5 times that of unstimulated cells. The bLF increased the production of proliferating cell nuclear antigen and rapid phosphorylation of the p44/ p42 mitogen-activated protein kinase in bMSF, but not in bMEC. The bLF-induced proliferation and production of proliferating cell nuclear antigen in bMSF was suppressed by U0126, a specific inhibitor of mitogenactivated protein kinase. Furthermore, treatment with bLF for $24 \mathrm{~h}$ decreased the mRNA levels of the 3 isoforms of transforming growth factor $\beta$ in bMSF (16-66\%) but upregulated those in bMEC (122-157\%). These opposite effects of bLF on the proliferation of epithelial and fibroblast cells and their expression of transforming growth factor $\beta$ may play a crucial role in bovine mammary involution and remodeling.

Key words: cell proliferation, lactoferrin, mammary epithelial cell, mammary stromal fibroblast

Received June 2, 2014.

Accepted October 28, 2014.

${ }^{1}$ Corresponding author: k1nakaji@affrc.go.jp

\section{Short Communication}

A nonlactating (i.e., dry) period between lactations is important for optimal milk production in dairy cows. During the dry period, mammary epithelial components undergo remodeling (Capuco et al., 1997; Sorensen et al., 2006) and the composition of mammary stromal tissue changes (De Vries et al., 2010). Fibroblasts, which are responsible for the synthesis and remodeling of the extracellular matrix, are the predominant cell type in mammary stroma. Interactions between mammary epithelial cells and the extracellular matrix are important for the functional differentiation of these cells (Barcellos-Hoff et al., 1989; Delabarre et al., 1997). Furthermore, cross-talk between epithelial and stromal cells occurs and the growth factors and cytokines produced by these cells influence the functions of other cell types (Cunha and Hom, 1996; Liotta and Kohn, 2001). In fact, hepatocyte growth factor derived from mammary stromal fibroblasts stimulates the growth of cultured murine mammary epithelial cells (Sasaki and Enami, 1999). Therefore, the epithelial-stromal interaction likely plays a key role in mammary involution and remodeling during dry periods.

Lactoferrin is an iron-binding glycoprotein belonging to the transferrin family (Anderson et al., 1989). Lactoferrin is produced mainly by glandular epithelial cells and is found in many physiologic fluids, including milk and colostrum (Steijns and van Hooijdonk, 2000). Lactoferrin is thought to be an important component of the mammalian host defense mechanism because of its potent antimicrobial, antiviral, and immunomodulatory activities (Hasegawa et al., 1994; Caccavo et al., 2002). In addition to the role of lactoferrin in host defense, accumulating evidence indicates that this glycoprotein has pleiotropic regulatory effects on cell migration, differentiation, and proliferation and on cytokine secretion (Ward et al., 2005; Tang et al., 2010). In particular, bovine lactoferrin (bLF) exerts both stimulatory and inhibitory effects on cell proliferation; bLF stimulates the proliferation of osteoblasts, bone marrow stromal cells, and myoblasts (Byatt et al., 1990; Cornish et al. 2004; Grey et al., 2004), but decreases the viability or 
proliferation of mammary epithelial cells, polyp fibroblasts, and breast cancer cell lines (Riley et al., 2008; Nadolska et al., 2010; Duarte et al. 2011). In addition, bLF induces apoptosis in human stomach cancer cell lines (Xu et al., 2010). The effect of bLF on cellular proliferation seems to be cell-type-specific, but the underlying mechanism is unknown.

The concentration of bLF in milk increases steadily as lactation progresses (Rainard et al., 1982; Cheng et al., 2008). In addition, bLF mRNA and protein levels in bovine mammary glands markedly increase after milking stops (Welty et al., 1976; Rejman et al. 1989; Schanbacher et al. 1993; Wilde et al. 1997). Therefore, the elevated bLF levels in mammary glands are likely to be associated with mammary involution and remodeling. In fact, bLF decreases the expression of casein and the proliferation of bovine mammary epithelial cells (bMEC) in vitro (Riley et al., 2008). Although lactoferrin is secreted by glandular epithelial cells (Steijns and van Hooijdonk, 2000), an immunohistochemical study has shown that bLF is localized in stromal areas during involution of the bovine mammary gland (Hurley and Rejman, 1993). Therefore, the bLF secreted by bMEC may penetrate the basement membrane and thus influence the functions of stromal cells. However, how bLF affects the proliferation of bovine mammary stromal fibroblasts (bMSF) remains to be clarified.

In the current study, we focused on bMSF to explore the roles of bLF in mammary involution and remodeling. To this end, we established primary cultured bMSF and their clones from bovine mammary glands and compared the effect of bLF on the proliferation of these cells with that on bMEC (Nakajima et al., 2008) in vitro. We also investigated potential differences in proliferation mechanisms between bMSF and bMEC.

The study was approved by the Animal Care Committee of NARO Hokkaido Agricultural Research Center. Two Holstein cows in midlactation were euthanized by intravenous overdose injection of pentobarbital sodium $(100 \mathrm{mg} / \mathrm{kg}$ of BW). Mammary tissues were removed within 20 min of death.

Primary bMSF were prepared by using a modification of a method used to isolate periodontal ligament fibroblasts (Okubo et al., 2010). In brief, mammary tissues obtained from lactating Holstein cows were dispersed in $120 \mathrm{U} / \mathrm{mL}$ of collagenase (Sigma Chemical, St. Louis, $\mathrm{MO})$. The cell suspension was filtered through a $150-\mu \mathrm{m}$ nylon mesh filter to remove undigested tissue fragments and debris. The filtrate then was centrifuged at $80 \times g$ for $10 \mathrm{~min}$ at room temperature. Cell clumps were removed and the supernatant was centrifuged at $120 \times g$ for $10 \mathrm{~min}$ at room temperature. The pelleted cells were washed twice with Dulbecco's modified Eagle's medium (DMEM; Sigma Chemical) containing 10\% (vol/vol) fetal calf serum (Hyclone, Logan, UT), $100 \mathrm{U} / \mathrm{mL}$ of penicillin, and $100 \mu \mathrm{g} / \mathrm{mL}$ of streptomycin (Sigma Chemical). Cells then were seeded into culture dishes (100 $\mathrm{mm}$ in diameter) coated with type I collagen and containing DMEM supplemented with $15 \%$ (vol/vol) fetal calf serum, $10 \mathrm{ng} / \mathrm{mL}$ of fibroblast growth factor 1 (R\&D Systems, Minneapolis, MN), $5 \mu \mathrm{g} / \mathrm{mL}$ of heparin (Sigma Chemical), $100 \mathrm{U} / \mathrm{mL}$ of penicillin, and $100 \mu \mathrm{g} /$ $\mathrm{mL}$ of streptomycin and cultured at $37^{\circ} \mathrm{C}$ in a humidified atmosphere of $5 \% \mathrm{CO}_{2}$ and $95 \%$ air. Cells obtained from passages 3 to 5 were used in subsequent studies.

To establish populations derived from single cells, the primary bMSF described previously were seeded into wells (1 cell/well) of a 96-well plastic plate coated with type I collagen (Becton Dickinson, Lincoln Park, NJ). The cells were maintained in DMEM supplemented with $15 \%$ (vol/vol) fetal bovine serum (Hyclone), 10 $\mathrm{ng} / \mathrm{mL}$ of fibroblast growth factor 1 (R\&D Systems), 5 $\mu \mathrm{g} / \mathrm{mL}$ of heparin, $100 \mathrm{U} / \mathrm{mL}$ of penicillin, and $100 \mu \mathrm{g} /$ $\mathrm{mL}$ of streptomycin. The culture medium was changed every $2 \mathrm{~d}$, and each well was monitored for cell growth and confluence. Once a well became confluent, the cells were expanded into a plastic dish (100 $\mathrm{mm}$ in diameter) coated with type I collagen. Four bMSF clones (CL1 through CL4) were established and used for additional experiments. Cells obtained from passages 6 to 10 were used in subsequent studies.

The isolation of bMEC clone was described previously (Nakajima et al., 2008). In brief, the mammary tissue from lactating Holstein cow was dispersed with $120 \mathrm{U} /$ $\mathrm{mL}$ of collagenase. The cell suspension was centrifuged at $80 \times g$ for $10 \mathrm{~min}$ at room temperature. The centrifuged cells and cell clumps were washed twice with RPMI-1640 medium (Sigma Chemical) supplemented with $10 \%$ (vol/vol) fetal bovine serum. The cells then were seeded into plastic dishes with RPMI-1640 medium supplemented with $10 \%$ (vol/vol) fetal bovine serum, $5 \mu \mathrm{g} / \mathrm{mL}$ of insulin, $100 \mathrm{U} / \mathrm{mL}$ of penicillin, and $100 \mu \mathrm{g} / \mathrm{mL}$ of streptomycin. After the cells became $80 \%$ confluent, we performed a limiting dilution of these cells and established cloned bMEC. The cloned bMEC were maintained in DMEM supplemented with $10 \%$ (vol/vol) fetal bovine serum, $5 \mu \mathrm{g} / \mathrm{mL}$ of insulin, 100 $\mathrm{U} / \mathrm{mL}$ of penicillin, and $100 \mu \mathrm{g} / \mathrm{mL}$ of streptomycin on noncoated plastic culture dishes.

Proliferation of bMSF and bMEC was determined by using a Cell Counting Kit 8 (Dojindo Laboratories, Kumamoto, Japan) according to the manufacturer's protocol. The bLF purified from milk was obtained from Wako (Osaka, Japan; purity greater than 95\%). In most cases (Figures 1,2B, and 3C), $5 \times 10^{3}$ cells were plated in each well of a 96-well tissue culture plate and cultured for $24 \mathrm{~h}$ in DMEM supplemented with $10 \%$ (vol/ vol) fetal bovine serum. Next, the cells were cultured in 
serum-free medium for $24 \mathrm{~h}$ (for serum starvation) and then treated with various concentrations of bLF (or the vehicle only) for $24 \mathrm{~h}$. In the case of 2 - to 6 -d culture of bMSF (Figure 2C), we used medium supplemented with $0.5 \%$ fetal bovine serum for the serum starvation, instead of serum-free medium. After the cells had been cultured with or without bLF for the various periods, 10 $\mu \mathrm{L}$ of WST-8 [2-(2-methoxy-4-nitrophenyl)-3-(4-nitrophenyl)- 5-(2,4-disulfophenyl)-2H-tetrazolium (monosodium salt; supplied with the kit)] was added directly to the culture medium of each well; subsequently, the cells were incubated at $37^{\circ} \mathrm{C}$ for 2 to $3 \mathrm{~h}$ for the reduction of WST- 8 by cellular dehydrogenases to give an orange product (formazan). The cell proliferation activity in each well was determined by reading the optical density at a wavelength of $450 \mathrm{~nm}$ with a microplate reader (MTP-800Lab, Corona Electric, Ibaraki, Japan). After subtraction of the reading for the cell-free blank, the relative cell proliferation activity after bLF stimulation was determined by comparison with the value obtained from unstimulated cells. Results are the means \pm SD of 8 samples. Significant differences between groups were analyzed by using Student's $t$-test or one-way ANOVA followed by Bonferroni's post-hoc test. $P$-values less than 0.05 were considered statistically significant. We investigated the levels of LPS contained in the bLF used in the current study by using limulus amoebocyte lysate methods. We found that $1,000 \mu \mathrm{g} / \mathrm{mL}$ of bLF dissolved in DMEM (maximal concentration of bLF used in Figures 1 and 2B) contained about $10.0 \mathrm{ng} /$ $\mathrm{mL}$ of LPS. We then confirmed that treatment with this concentration of LPS for $24 \mathrm{~h}$ did not affect the proliferation status of either bMSF or bMEC cultured in serum-free DMEM by using a colorimetric assay (data not shown). We also confirmed that $1.0 \mathrm{ng} / \mathrm{mL}$ of LPS, which was the concentration estimated to be contained in the bLF used in Figure 2C, did not affect the proliferation status of bMSF cultured in DMEM supplemented with $0.5 \%$ fetal bovine serum for 2 to 6 d (data not shown).

For reverse transcription-PCR analyses, total RNA was extracted from bMSF and bMEC by using Isogen (Nippongene, Toyama, Japan) according to the manufacturer's protocol. The cDNA was synthesized by using Moloney murine leukemia virus reverse transcriptase (Sigma Chemical) and random primers. The primer sequences used for PCR amplification were designed by using Primer3 (Rozen and Skaletsky, 2000) and are shown in Table 1. The mRNA expression of transforming growth factor $\beta$ (TGF $\boldsymbol{\beta} 1$, TGF $\boldsymbol{\beta 2}$, TGF $\boldsymbol{3 3}$ ) was measured by real-time quantitative RT-PCR amplification using SYBR PreMix Ex TaqII (Takara Bio, Shiga, Japan). The thermal cycling conditions were initial denaturation at $95^{\circ} \mathrm{C}$ for $30 \mathrm{~s}$, followed by 40 cycles of $95^{\circ} \mathrm{C}$ for $5 \mathrm{~s}, 58^{\circ} \mathrm{C}$ for $15 \mathrm{~s}$, and $72^{\circ} \mathrm{C}$ for $34 \mathrm{~s}$. Data were normalized against the corresponding amount of $\beta$-actin mRNA and are means $\pm \mathrm{SD}$ of triplicate determinations. Significant differences between groups were analyzed by using one-way ANOVA followed by Bonferroni's post hoc test. $P$-values less than 0.05 were considered statistically significant.

For Western blot analysis, cells were washed twice with PBS, resuspended in sampling buffer $[62.5 \mathrm{mM}$ Tris-HCl (pH 6.8), 2\% (wt/vol) SDS, $50 \mathrm{~m} M$ dithiothreitol, and $10 \%$ (vol/vol) glycerol], and boiled for 10 min. Equal amounts of total protein from each cell lysate underwent 10\% (wt/vol) denaturing PAGE and were transferred onto a polyvinylidene fluoride membrane (Millipore, Bedford, MA) by semi-dry blotting. Western blotting with phospho-specific p44/p42 mitogen-activated protein kinase (MAPK) antibody (1:1,000; New England BioLabs, Beverly, MA), total p44/p42 MAPK antibody (1:1,000; New England BioLabs), proliferating cell nuclear antigen (PCNA) antibody (1:1,000; AbD Serotec, Oxford, UK), or $\beta$-actin antibody (1:100; AnaSpec, San Jose, CA) was performed by using alkaline phosphatase-labeled secondary antibodies. Detection was carried out by using

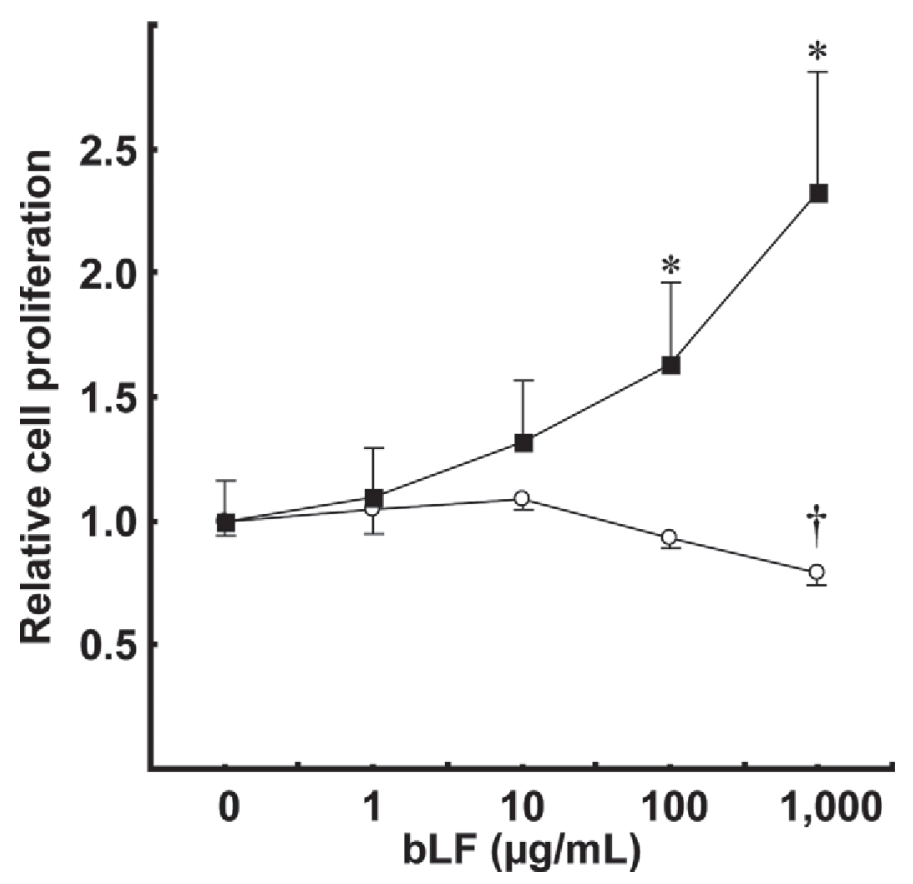

Figure 1. Effects of bovine lactoferrin (bLF) on the proliferation of primary bovine mammary stromal fibroblasts (bMSF; $\mathbf{0}$ ) and bovine mammary epithelial cells (bMEC; $\bigcirc$ ). Cells were treated for $24 \mathrm{~h}$ with the indicated doses of bLF. Cell proliferation was measured by using a colorimetric assay, and the proliferation rate was calculated relative to that of unstimulated cells. Each value represents the mean $\pm \mathrm{SD}$ of 8 samples. Values differ significantly $(P<0.05$; ANOVA followed by Bonferroni's multiple-comparisons test) from those of unstimulated $\operatorname{bMSF}(*)$ or bMEC $(\dagger)$. 
A

\section{CL1}

\section{CL4}
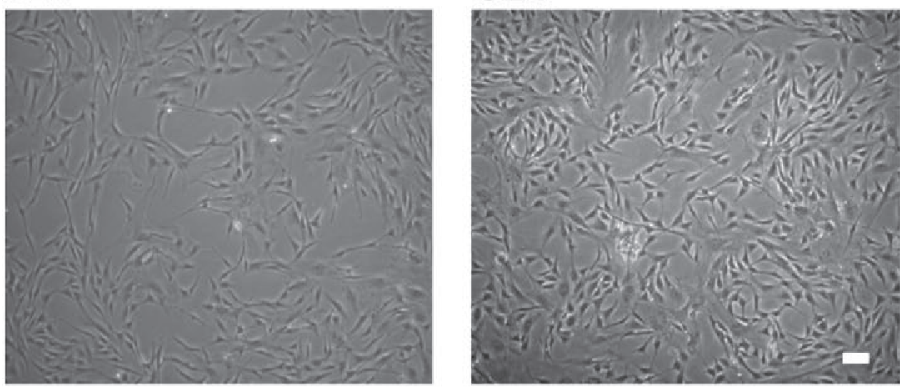

B
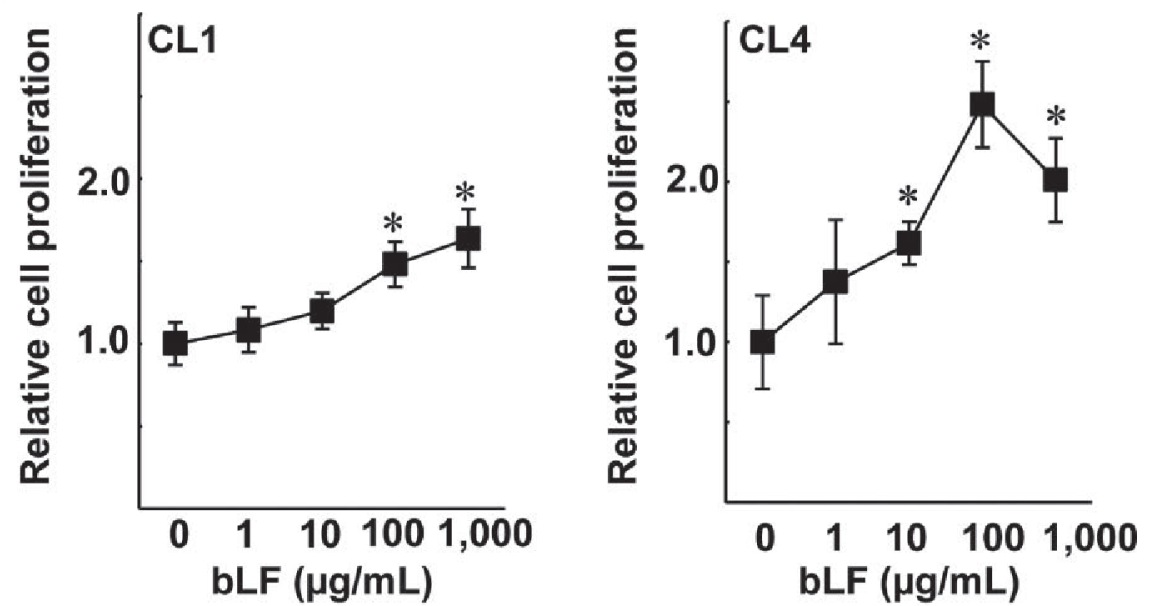

C

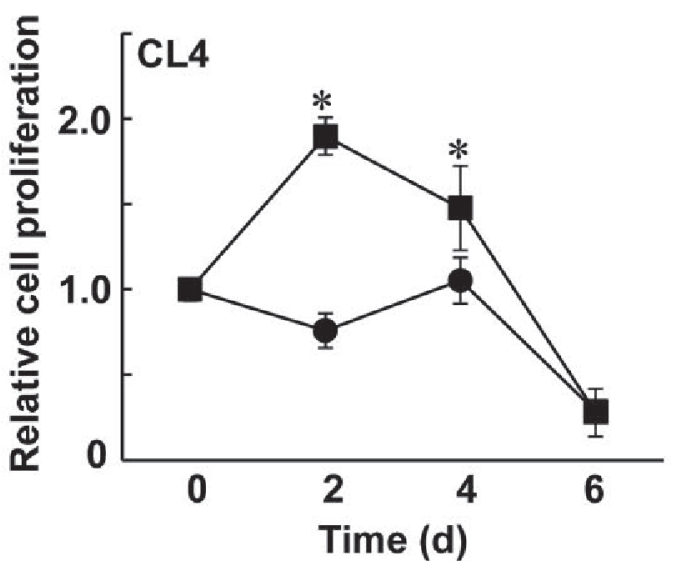

Figure 2. Morphologic characterization and proliferation of bovine mammary stromal fibroblast (bMSF) clones. (A) Morphologic characterization of established bMSF clones (CL1 and CL4) viewed by phase-contrast microscopy. Scale bar $=100 \mu \mathrm{m}$. (B) Proliferation of bMSF clones, CL1 and CL4, after treatment with various doses of bovine lactoferrin (bLF). Cell proliferation was measured by using a colorimetric assay, and proliferation rates were calculated relative to those of unstimulated cells. Each value represents the mean \pm SD of 8 samples. An asterisk $(*)$ means values differ significantly $(P<0.05$; ANOVA followed by Bonferroni's multiple-comparisons test) from that of unstimulated cells. (C) Time course of proliferation status of bMSF (CL4) cultured with bLF for 2 to $6 \mathrm{~d}$. Cells were plated in each well of a 96-well tissue culture plate and cultured in Dulbecco's modified Eagle's medium (DMEM) supplemented with $10 \%$ (vol/vol) fetal bovine serum for $24 \mathrm{~h}$. The cells were further cultured in the DMEM supplemented with $0.5 \%$ (vol/vol) fetal bovine serum for $24 \mathrm{~h}$ and then treated with $100 \mu \mathrm{g} / \mathrm{mL}$ of bLF ( $\mathbf{a}$ ) or vehicle $(\bullet)$ for the indicated periods. The culture medium was changed every day. The proliferative activity of bMSF was evaluated at d 2 to 6 after bLF stimulation and the proliferation rates were calculated relative to that of unstimulated cells on $\mathrm{d} 0$. Each value represents the mean \pm SD of 8 samples. An asterisk $\left(^{*}\right)$ means values differ significantly $(P<0.05$; Student's $t$-test $)$ from that of unstimulated cells. 
A

bMSF
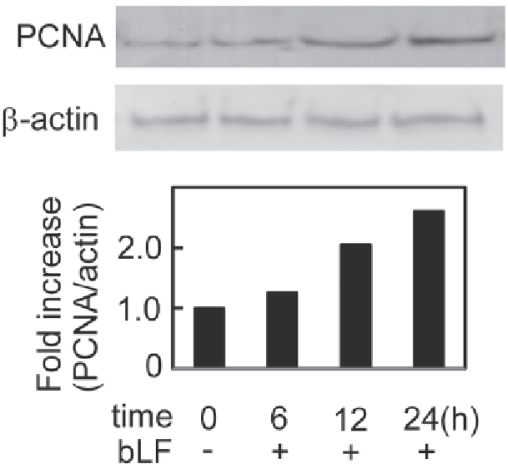

B

bMSF

P-p44/p42 MAPK

T-p44/p42 MAPK

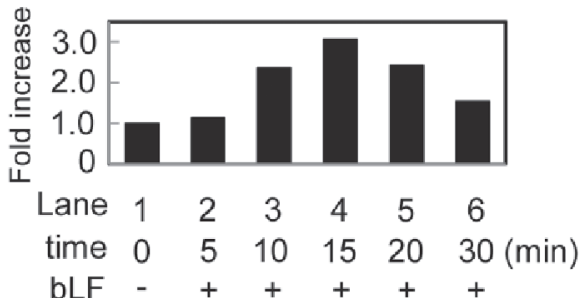

C

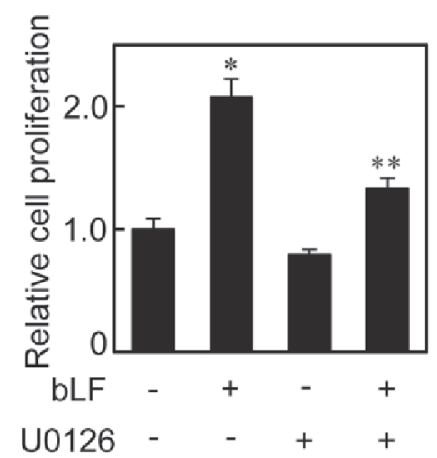

bMEC
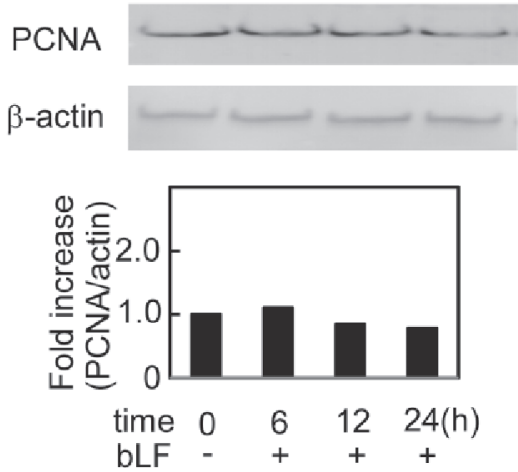

bMEC

P-p44/p42 MAPK

T-p44/p42 MAPK

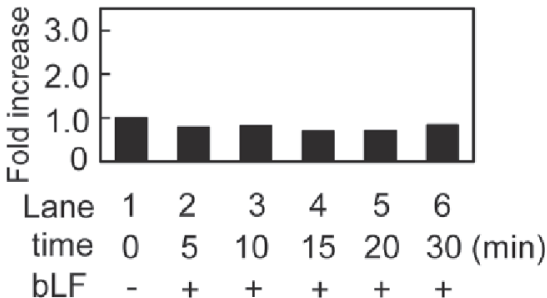

D
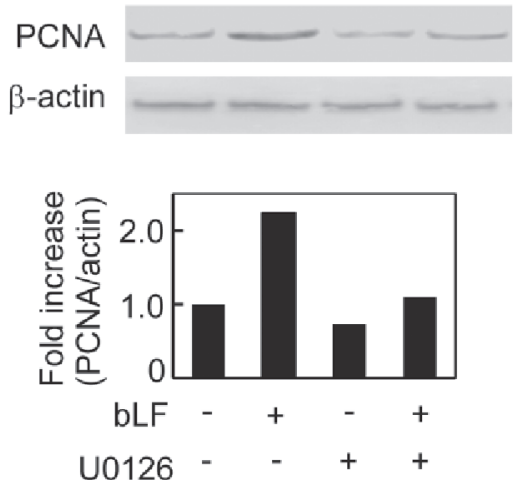

Figure 3. Involvement of p44/p42 mitogen-activated protein kinase (MAPK) in bovine lactoferrin (bLF)-mediated proliferation in bovine mammary stromal fibroblasts (bMSF). (A) Effects of bLF on the production of proliferating cell nuclear antigen (PCNA) in cultured bMSF (CL4) and bovine mammary epithelial cells (bMEC). Cells were treated with $100 \mu \mathrm{g} / \mathrm{mL}$ of bLF for the indicated periods. Cell extracts were evaluated through Western blot analysis using antibody against PCNA or $\beta$-actin. Similar results were obtained for 2 additional, different cell preparations (data not shown). (B) Effects of bLF on p44/p42 MAPK phosphorylation in cultured bMSF (CL4) and bMEC. Cells were treated with $100 \mu \mathrm{g} / \mathrm{mL}$ of bLF for the indicated periods. Cell extracts were subjected to Western blot analysis using antibody against phospho-specific p44/p42 MAPK (P-p44/p42 MAPK) or total-p44/p42 MAP kinase (T-p44/p42 MAPK). Similar results were obtained with 2 additional, different cell preparations (data not shown). (C, D) Effects of U0126 (Calbiochem-Novabiochem, La Jolla, CA) on bLF-mediated proliferation and PCNA in cultured bMSF (CL4). Cells were treated with $5 \mu M$ U0126 or vehicle for $60 \mathrm{~min}$ and then treated with $100 \mu \mathrm{g} / \mathrm{mL}$ of bLF for $24 \mathrm{~h}$. (C) Cell proliferation was measured and the proliferation rates calculated relative to that of unstimulated cells. Each value represents the mean \pm SD of 8 samples. (D) Cell extracts were subjected to Western blot analysis with antibody against PCNA or $\beta$-actin. Similar results were obtained with 2 additional, different cell preparations (data not shown). 
Table 1. Sequences of primers used for PCR

\begin{tabular}{|c|c|c|c|}
\hline Target $^{1}$ & Oligonucleotide sequence $\left(5^{\prime}-3^{\prime}\right)$ & $\begin{array}{l}\text { Accession } \\
\text { number }\end{array}$ & $\begin{array}{l}\text { Predicted } \\
\text { size (bp) }\end{array}$ \\
\hline TGF $\beta 1$ & $\begin{array}{l}\text { CACGTGGAGCTGTACCAGAA } \\
\text { GCGAAAGCCCTCTATTTCCT }\end{array}$ & NM_001166068 & 156 \\
\hline TGF $\beta 2$ & $\begin{array}{l}\text { AGAGCCCACATCTCCTGCTA } \\
\text { TGGCATTGTACCCTTTAGGC }\end{array}$ & NM_001113252 & 201 \\
\hline TGF $\beta 3$ & $\begin{array}{l}\text { TCTGGGGCGACTTAAGAAGA } \\
\text { CACACAGCAGTTCTCCTCCA }\end{array}$ & BC149207 & 157 \\
\hline$\beta$-Actin & $\begin{array}{l}\text { AGGTCATCACCATCGGCAAT } \\
\text { TCGTGAATGCCGCAGGAT }\end{array}$ & AY141970 & 91 \\
\hline
\end{tabular}

${ }^{1} \mathrm{TGF} \beta=$ transforming growth factor $\beta$.

nitroblue tetrazolium and 5-bromo-4-chloro-3-indoxyl phosphate (Roche Applied Science, Indianapolis, IN). The signal intensity of each band on the Western blot was quantified by using Image J software (National Institutes of Health, Bethesda, MD).

To investigate whether $\mathrm{p} 44 / \mathrm{p} 42$ MAPK was involved in bLF-induced proliferation and PCNA induction in bMSF, we added U0126 (Calbiochem-Novabiochem, La Jolla, CA), a specific inhibitor of MAPK, which activates $\mathrm{p} 44 / \mathrm{p} 42$ MAPK, to the bLF-stimulated cells. For analysis of PCNA induction, bMSF (CL4) were plated in plastic dishes (diameter, $35 \mathrm{~mm}$ ) in DMEM supplemented with $10 \%$ (vol/vol) fetal bovine serum and cultured until the cells were $80 \%$ confluent. These cells were cultured in DMEM alone for $24 \mathrm{~h}$. The cells were then stimulated by treatment with $100 \mu \mathrm{g} / \mathrm{mL}$ of bLF (or the vehicle only) for $24 \mathrm{~h}$. In addition, some cells were pretreated with $5 \mu M$ U0126 for 60 min. Cells were harvested after $24 \mathrm{~h}$ of bLF treatment and Western blot analysis of PCNA protein was performed as described previously.

A primary culture of bMSF was established, and all cells exhibited a fibroblast phenotype (data not shown). The effect of bLF on the proliferation of these bMSF cells was compared with that of previously cloned bMEC (Nakajima et al., 2008; Figure 1). Addition of $\mathrm{bLF}$ at $100 \mu \mathrm{g} / \mathrm{mL}$ or greater to the culture medium increased the proliferation of primary bMSF (Figure 1). The maximal effect occurred at $1,000 \mu \mathrm{g} / \mathrm{mL}$ of bLF, such that the proliferation of bMSF was approximately 2.5 times that of unstimulated cells $(P<0.05)$. Similar results were obtained for other primary bMSF cultures prepared from a different cow. In contrast, bLF decreased the proliferation of bMEC. Specifically, the proliferation of bMEC treated with $1,000 \mu \mathrm{g} / \mathrm{mL}$ of bLF was about $20 \%$ lower $(P<0.05)$ than that of unstimulated cells. This inhibitory effect of bLF on bMEC is in accordance with results reported for primary bMEC and for bMEC cell lines (Hurley et al., 1994; Riley et al., 2008). In addition, Riley et al. (2008) reported that
bLF at $1,000 \mu \mathrm{g} / \mathrm{mL}$ significantly inhibited the mRNA expression of $\beta-\mathrm{CN}$. The concentration of bLF in milk increases steadily as lactation progresses (Rainard et al., 1982; Cheng et al., 2008), from $30 \mu \mathrm{g} / \mathrm{mL}$ at $30 \mathrm{~d}$ after calving to $60 \mu \mathrm{g} / \mathrm{mL}$ at $150 \mathrm{~d}$ and $150 \mu \mathrm{g} / \mathrm{mL}$ at $270 \mathrm{~d}$ (Rainard et al., 1982). In addition, the levels of bLF mRNA and protein in bovine mammary glands further increase after cessation of milking (Welty et al., 1976; Rejman et al., 1989; Schanbacher et al., 1993; Wilde et al., 1997); bLF levels can exceed 1,500 $\mu \mathrm{g} /$ $\mathrm{mL}$ at 2 to $4 \mathrm{~d}$ after cessation of milking (Welty et al., 1976; Rejman et al., 1989). Therefore, the increased concentrations of bLF in late lactation and after cessation of milking may stimulate the proliferation of bMSF but inhibit that of bMEC. These effects may contribute to involution in bovine mammary glands.

Primary cultured bMSF are a heterogeneous population in regard to their potential for proliferation. To minimize this heterogeneity and to exclude the possibility that other cell types may have contaminated the primary bMSF cultures, primary bMSF cultures were subjected to limiting dilution and were used to generate 4 clones, CL1 through CL4, each of which was derived from a single cell and contained fibroblastic spindles. Figure 2A gives examples of photographs of 2 clones (CL1 and CL4). Immunostaining revealed that all 4 clones were positive for the mesenchymal cell marker vimentin and negative for the epithelial cell marker cytokeratin (data not shown). Figure 2B gives examples of the proliferation analysis of 2 clones (CL1 and CL4); bLF stimulated the proliferation of both CL1 and CL4, although slight differences were present between clones. The peak effect occurred at $100 \mu \mathrm{g} / \mathrm{mL}$ of bLF for CL4 and at 1,000 $\mathrm{gg} / \mathrm{mL}$ of bLF for CL1. We also evaluated the proliferation status of bMSF 2 to $6 \mathrm{~d}$ after bLF stimulation. The proliferative activity of bMSF was significantly enhanced at d 2 and 4 but not at $\mathrm{d} 6$ after bLF stimulation, compared with that in the unstimulated cells (Figure 2C). We then used Western blotting to determine the effect of bLF on the expres- 

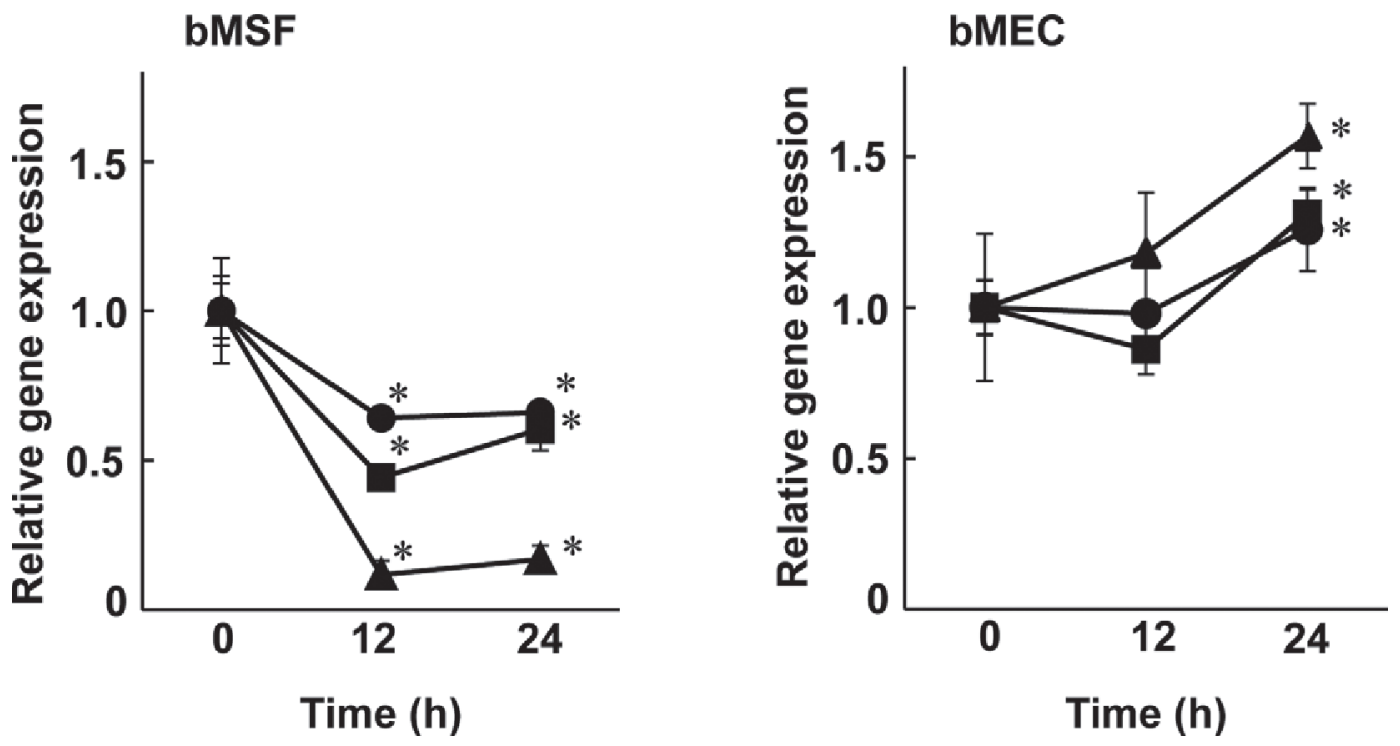

Figure 4. Expression of transforming growth factor $\beta$ (TGF $\beta$ ) mRNA in cultured bovine mammary stromal fibroblasts (bMSF, CL4) and bovine mammary epithelial cells (bMEC) after treatment with $100 \mu \mathrm{g} / \mathrm{mL}$ of bovine lactoferrin (bLF). The relative mRNA expression levels of

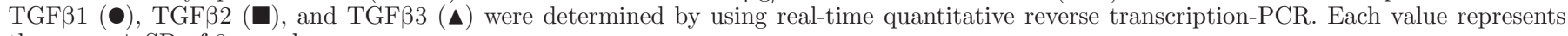
the mean $\pm \mathrm{SD}$ of 8 samples.

sion of the proliferation marker PCNA. After 12 to 24 $\mathrm{h}$ of treatment with bLF, PCNA levels were increased in bMSF but slightly decreased in bMEC (Figure 3A).

To gain further insight into the mechanisms underlying bLF-stimulated cell proliferation, we investigated the effect of bLF on the phosphorylation of $\mathrm{p} 44 / \mathrm{p} 42$ MAPK in bMSF and bMEC. The bLF induced rapid phosphorylation of $\mathrm{p} 44 / \mathrm{p} 42$ MAPK in bMSF; peak phosphorylation occurred 15 min after treatment with bLF and was approximately 3 times that of untreated cells (Figure 3B). In contrast, bLF did not affect the phosphorylation of $\mathrm{p} 44 / \mathrm{p} 42$ MAPK in bMEC (Figure 3B). In addition, treatment with U0126 $(5 \mu M)$ caused about a $50 \%$ reduction $(P<0.05)$ in the bLF-mediated proliferation of bMSF (Figure 3C) and inhibited PCNA induction in bMSF (Figure 3D). Because bLF is a ligand of low-density lipoprotein receptor-related proteins 1 and 2 (LRP1 and LRP2; Willnow et al., 1992; Ji and Mahley, 1994; Vash et al. 1998; Neels et al., 1999), we then used semiquantitative RT-PCR to explore the mRNA expression of these receptors. The LRP1 mRNA level in bMSF was higher than that in bMEC. In contrast, the LRP2 mRNA level was lower in bMSF than that in bMEC (data not shown). The bLF stimulates osteoblast mitogenesis by enhancing LRP1mediated p44/p42 MAPK signaling (Grey et al., 2004). Therefore, p44/p42 MAPK may be phosphorylated in response to the binding of bLF to LRP1.

Transforming growth factor $\beta$ is a multifunctional growth factor that regulates cell proliferation and dif- ferentiation and extracellular matrix production (Verrecchia and Mauviel, 2002). Mammals have 3 TGF $\beta$ isoforms-TGF $\beta 1$, TGF 32 , and TGF 33 - which are encoded by 3 different genes (Derynck et al., 1988). In general, TGF $\beta$ inhibits mammary epithelial growth and milk protein synthesis (Plaut, 1993). In cows, all 3 TGF $\beta$ isoforms can be detected in both lactating and nonlactating mammary glands, although the distributions of the various isoforms differ (Maier et al., 1991). The TGF $\beta 1$ exerts both antiproliferative and apoptotic effects in the bMEC line BME-UV1 in vitro (Kolek et al., 2003). Thus, we investigated how bLF affected the expression status of TGF $\beta$ in bMSF and bMEC. The mRNA levels of all 3 TGF $\beta$ isoforms were decreased $(P<0.05) 12$ to $24 \mathrm{~h}$ after treatment of bMSF with bLF. In comparison, the expression of these mRNA was unchanged at $12 \mathrm{~h}$ but upregulated $(P<0.05) 24$ $\mathrm{h}$ after the treatment of bMEC with bLF (Figure 4). Because TGF $\beta$ inhibit the growth of bMEC and mammary fibroblasts in vitro (Woodward et al., 1995), the bLF-induced expression of TGF $\beta$ in bMEC autocrinely or paracrinely inhibits proliferative activity of these cells, whereas the bLF-induced suppression of TGF $\beta$ expression in bMSF contributes to positive control of the proliferative activity of bMSF. In addition, TGF $\beta$ is an important regulator of tissue remodeling because of its capacity to stimulate the deposition of extracellular matrix when injected into tissue in vivo (Roberts et al., 1990). In fact, treatment of prepubertal bovine mammary glands with exogenous TGF $\beta 1$ in slow-release 
plastic pellets increases fibronectin expression (Musters et al., 2004). Therefore, bLF-regulated TGF $\beta$ expression may affect the remodeling of mammary gland via the production of extracellular matrix.

In conclusion, our results demonstrated that bLF increased the proliferation of bMSF but decreased that of bMEC. Furthermore, treatment with bLF decreased the mRNA levels of TGF $\beta$ in bMSF but upregulated those in bMEC. These opposite effects of bLF on the proliferation of fibroblasts and epithelial cells and their expression of TGF $\beta$ may play a crucial role in bovine mammary involution and remodeling.

\section{ACKNOWLEDGMENTS}

This work was supported in part by the Akiyama Life Science Foundation (Sapporo, Japan). We are grateful to the staff of the Research Support Center at NARO Hokkaido Agricultural Research Center for their help with animal management.

\section{REFERENCES}

Anderson, B. F., H. M. Baker, G. E. Norris, D. W. Rice, and E. N. Baker. 1989. Structure of human lactoferrin: Crystallographic structure analysis and refinement at 2.8 A resolution. J. Mol. Biol. 209:711-734.

Barcellos-Hoff, M. H., J. Aggeler, T. G. Ram, and M. J. Bissell. 1989. Functional differentiation and alveolar morphogenesis of primary mammary cultures on reconstituted basement membrane. Development 105:223-235.

Byatt, J. C., J. J. Schmuke, P. G. Comens, D. A. Johnson, and R. J. Collier. 1990. The effect of bovine lactoferrin on muscle growth in vivo and in vitro. Biochem. Biophys. Res. Commun. 173:548-553.

Caccavo, D., N. M. Pellegrino, M. Altamura, A. Rigon, L. Amati, A. Amoroso, and E. Jirillo. 2002. Antimicrobial and immunoregulatory functions of lactoferrin and its potential therapeutic application. J. Endotoxin Res. 8:403-417.

Capuco, A. V., R. M. Akers, and J. J. Smith. 1997. Mammary growth in Holstein cows during the dry period: Quantification of nucleic acids and histology. J. Dairy Sci. 80:477-487.

Cheng, J. B., J. Q. Wang, D. P. Bu, G. L. Liu, C. G. Zhang, H. Y. Wei, L. Y. Zhou, and J. Z. Wang. 2008. Factors affecting the lactoferrin concentration in bovine milk. J. Dairy Sci. 91:970-976.

Cornish, J., K. E. Callon, D. Naot, K. P. Palmano, T. Banovic, U. Bava, M. Watson, J. M. Lin, P. C. Tong, Q. Chen, V. A. Chan, H. E. Reid, N. Fazzalari, H. M. Baker, E. N. Baker, N. W. Haggarty, A. B. Grey, and I. R. Reid. 2004. Lactoferrin is a potent regulator of bone cell activity and increases bone formation in vivo. Endocrinology 145:4366-4374.

Cunha, G. R., and Y. K. Hom. 1996. Role of mesenchymal-epithelial interactions in mammary gland development. J. Mammary Gland Biol. Neoplasia 1:21-35.

De Vries, L. D., H. Dover, T. Casey, M. J. VandeHaar, and K. Plaut. 2010. Characterization of mammary stromal remodeling during the dry period. J. Dairy Sci. 93:2433-2443.

Delabarre, S., C. Claudon, and F. Laurent. 1997. Influence of several extracellular matrix components in primary cultures of bovine mammary epithelial cells. Tissue Cell 29:99-106.

Derynck, R., P. B. Lindquist, A. Lee, D. Wen, J. Tamm, J. L. Graycar, L. Rhee, A. J. Mason, D. A. Miller, and R. J. Coffey. 1988. A new type of transforming growth factor- $\beta$, TGF- $\beta 3$. EMBO J. $7: 3737-3743$.
Duarte, D. C., A. Nicolau, J. A. Teixeira, and L. R. Rodrigues. 2011. The effect of bovine milk lactoferrin on human breast cancer cell lines. J. Dairy Sci. 94:66-76.

Grey, A., T. Banovic, Q. Zhu, M. Watson, K. Callon, K. Palmano, J. Ross, D. Naot, I. R. Reid, and J. Cornish. 2004. The low-density lipoprotein receptor-related protein 1 is a mitogenic receptor for lactoferrin in osteoblastic cells. Mol. Endocrinol. 18:2268-2278.

Hasegawa, K., W. Motsuchi, S. Tanaka, and S. Dosako. 1994. Inhibition with lactoferrin of in vitro infection with human herpes virus. Jpn. J. Med. Sci. Biol. 47:73-85.

Hurley, W. L., H. M. Hegarty, and J. T. Metzler. 1994. In vitro inhibition of mammary cell growth by lactoferrin: A comparative study. Life Sci. 55:1955-1963.

Hurley, W. L., and J. J. Rejman. 1993. Bovine lactoferrin in involuting mammary tissue. Cell Biol. Int. 17:283-289.

Ji, Z. S., and R. W. Mahley. 1994. Lactoferrin binding to heparin sulfate proteoglycans and the LDL receptor-related protein. Further evidence supporting the importance of direct binding of remnant lipoproteins to HSPG. Arterioscler. Thromb. 14:2025-2031.

Kolek, O., B. Gajkowska, M. M. Godlewski, and T. Motyl. 2003. Antiproliferative and apoptotic effect of TGF- $\beta 1$ in bovine mammary epithelial BME-UV1 cells. Comp. Biochem. Physiol. C Toxicol. Pharmacol. 134:417-430.

Liotta, L. A., and E. C. Kohn. 2001. The microenvironment of the tumour-host interface. Nature 411:375-379.

Maier, R., P. Schmid, D. Cox, G. Bilbe, and G. K. McMaster. 1991. Localization of transforming growth factor- $\beta 1,-\beta 2$, and $-\beta 3$ gene expression in bovine mammary gland. Mol. Cell. Endocrinol. 82:191-198.

Musters, S., K. Coughlan, T. McFadden, R. Maple, T. Mulvey, and K. Plaut. 2004. Exogenous TGF- $\beta 1$ promotes stromal development in the heifer mammary gland. J. Dairy Sci. 87:896-904.

Nadolska, B., M. Frączek, T. Kręcicki, M. Kocięba, and M. Zimecki. 2010. Lactoferrin inhibits the growth of nasal polyp fibroblasts. Pharmacol. Rep. 62:1139-1147.

Nakajima, K., M. Nakamura, X. D. Gao, and T. Kozakai. 2008. Possible involvement of prolactin in the synthesis of lactoferrin in bovine mammary epithelial cells. Biosci. Biotechnol. Biochem. 72:1103-1106.

Neels, J. G., B. M. van Den Berg, A. Lookene, G. Olivecrona, H. Pannekoek, and A. J. van Zonneveld. 1999. The second and fourth cluster of class a cysteine-rich repeats of the low-density lipoprotein receptor-related protein share ligand-binding properties. J. Biol. Chem. 274:31305-31311.

Okubo, N., A. Ishisaki, T. Iizuka, M. Tamura, and Y. Kitagawa. 2010. Vascular cell-like potential of undifferentiated ligament fibroblasts to construct vascular cell-specific marker-positive blood vessel structures in a PI3K activation-dependent manner. J. Vasc. Res. $47: 369-383$.

Plaut, K. 1993. Role of epidermal growth factor and transforming growth factors in mammary development and lactation. J. Dairy Sci. 76:1526-1538.

Rainard, P., B. Poutrel, and J. P. Caffin. 1982. Lactoferrin and transferrin in bovine milk in relation to certain physiological and pathological factors. Ann. Rech. Vet. 13:321-328.

Rejman, J. J., W. L. Hurley, and J. M. Bahr. 1989. Enzyme-linked immunosorbent assays of bovine lactoferrin and a 39-kilodalton protein found in mammary secretions during involution. J. Dairy Sci. 72:555-560.

Riley, L. G., P. Williamson, P. C. Wynn, and P. A. Sheehy. 2008. Lactoferrin decreases primary bovine mammary epithelial cell viability and casein expression. J. Dairy Res. 75:135-141.

Roberts, A. B., U. I. Heine, K. C. Flanders, and M. B. Sporn. 1990. Transforming growth factor- $\beta$. Major role in regulation of extracellular matrix. Ann. N. Y. Acad. Sci. 580:225-232.

Rozen, S., and H. Skaletsky. 2000. Primer3 on the WWW for general users and for biologist programmers. Methods Mol. Biol. 132:365-386.

Sasaki, M., and J. Enami. 1999. Mammary fibroblast-derived hepatocyte growth factor and mammogenic hormones stimulate the 
growth of mouse mammary epithelial cells in primary culture. Endocr. J. 46:359-366.

Schanbacher, F. L., R. E. Goodman, and R. S. Talhouk. 1993. Bovine mammary lactoferrin: Implications from messenger ribonucleic acid (mRNA) sequence and regulation contrary to other milk proteins. J. Dairy Sci. 76:3812-3831.

Sorensen, M. T., J. V. Nørgaard, P. K. Theil, M. Vestergaard, and K. Sejrsen. 2006. Cell turnover and activity in mammary tissue during lactation and the dry period in dairy cows. J. Dairy Sci. 89:4632-4639.

Steijns, J. M., and A. C. van Hooijdonk. 2000. Occurrence, structure, biochemical properties and technological characteristics of lactoferrin. Br. J. Nutr. 84:S11-S17.

Tang, L., T. Cui, J. J. Wu, W. Liu-Mares, N. Huang, and J. Li. 2010 A rice-derived recombinant human lactoferrin stimulates fibroblast proliferation, migration, and sustains cell survival. Wound Repair Regen. 18:123-131.

Vash, B., N. Phung, S. Zein, and D. DeCamp. 1998. Three complement-type repeats of the low-density lipoprotein receptor-related protein define a common binding site for RAP, PAI-1, and lactoferrin. Blood 92:3277-3285.

Verrecchia, F., and A. Mauviel. 2002. Transforming growth factor- $\beta$ signaling through the Smad pathway: Role in extracellular matrix gene expression and regulation. J. Invest. Dermatol. 118:211-215.
Ward, P. P., E. Paz, and O. M. Conneely. 2005. Multifunctional roles of lactoferrin: A critical overview. Cell. Mol. Life Sci. 62:2540-2548.

Welty, F. K., K. L. Smith, and F. L. Schanbacher. 1976. Lactoferrin concentration during involution of the bovine mammary gland. J. Dairy Sci. 59:224-231.

Wilde, C. J., C. V. Addey, P. Li, and D. G. Fernig. 1997. Programmed cell death in bovine mammary tissue during lactation and involution. Exp. Physiol. 82:943-953.

Willnow, T. E., J. L. Goldstein, K. Orth, M. S. Brown, and J. Herz. 1992. Low-density lipoprotein receptor-related protein and gp330 bind similar ligands, including plasminogen activator-inhibitor complexes and lactoferrin, an inhibitor of chylomicron remnant clearance. J. Biol. Chem. 267:26172-26180.

Woodward, T. L., N. Dumont, M. O'Connor-McCourt, J. D. Turner, and A. Philip. 1995. Characterization of transforming growth factor- $\beta$ growth regulatory effects and receptors on bovine mammary cells. J. Cell. Physiol. 165:339-348.

Xu, X. X., H. R. Jiang, H. B. Li, T. N. Zhang, Q. Zhou, and N. Liu. 2010. Apoptosis of stomach cancer cell SGC-7901 and regulation of Akt signaling way induced by bovine lactoferrin. J. Dairy Sci. 93:2344-2350. 